\title{
Política nacional de desarrollo y dependencia externa*
}

\begin{abstract}
OSVALDO SUNKE es Profesor de Desarrollo Económico de la Escuela de Economia de la Liniversidad de Chile y Director del Projecto de Investigación del Desarrollo Económico en el Instituto Latinoamericano de Planificación Económica y Social. Este articulo es una rersión revisada de una conferencia dietada el 17 de noviembre de 1966 en el Salón de flonor de la Universidad de Chile, dentro del Ciclo de Conferencias Inaugurales del Instituto de Estudios Internacionales de dicha Universidad.
\end{abstract}

\section{PLANTEAMIENTO DEL PROBLEMA}

El desarrollo, apreciado en una perspectiva histórica adecuada, aparece en último término como un proceso de transformación de estructuras e instituciones económicas, sociales, politicas y culturales. La politica nacional de desarro. llo, para ser eficaz, consiste en impulsar y promover cambios estructurales e institucionales que se consideran imprescindibles para cumplir objetivos sociales determinados. Ello implica necesariamente la alteración de situaciones tradicionalmente aceptadas y por consiguiente el desafio a intereses creados en torno a esas situaciones, tanto en el plano interno como en el internacional. Puede afirmarse entonces que la política de desarrollo de nuestros países - en cuanto a sus objetivos, intensidad, instrumentalización y eficacia- se encuentra enmarcada dentro de ciertos márgenes de flexibilidad; su "libertad de maniobra" dependerá principalmente de la situación interna y de las vinculaciones internacionales del país.

Por lo que se refiere a la situación interna, ésta se ve afectada con el transcurso del ciempo por las alteraciones que el propio proceso de desarrollo acarrea: la inclustrialización, la urbanización, la difcrenciación ocupacional, los cambios en la estructura social, las alteraciones de actitudes y valores, las modificaciones en los patrones de la participación política, las transformaciones en la función social de la mujer, los cambios tecnológicos en los medios

- Este trabajo debe mitcho a las ideas que Aníbal P'into ha venido chaborando sobre cl tema, asi como a sus cotnentarios especificos sobre una versión anterior. Sin embargo, ha opiniones que aqui expreso son de mi cxelusiva responabilidad. 


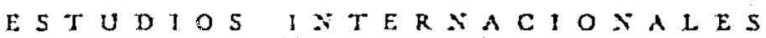

de comunicación y de información de la masa popular, los cambios en la magnitud $y$ funciones del estado, etc.

En lo que atañe a las vinculaciones externas de nuestros paises, la influen. cia que éstas ejercen respecto de la política nacional de desarrollo derivan del hecho de enconturnos insertados en el sistema de relaciones internacionales del mundo capitalista. liste se caracteriza por la presencia de una potencia dominante, una serie de potencias intermedias y los paises subdesarrollados adscritos al bloque capitalista. El sistema de relaciones internacionales del que formamos parte también es -como la situación interna- esencialmente dinámico. Experimenta variaciones significativas, tanto por los cambios internos de los paises señalados, como a consecuencia de las alternativas por las que pasa en su constante confrontación con el otro sistema principal de relaciones internacionales, el mundo socialista, encabezado también por una potencia dominante. Dichas alternativas en la gran confrontación mundial hacen variar los limites externos dentro de los cuales se muere la política nacional de desarrollo en los países que forman parte de uno u otro sistema de relaciones internacionales.

Todo lo anterior no constituye, por supuesto, ninguna novedad. Toda persona medianamente informada, y también el gxan iúblico de nuestros países. saben perfectamente que la política, en general, y la politica de desarrollo, en particular, se mueve dentro de condiciones externas que en ciertos periodos estrechan, y en otros amplian, su libertad de maniobra. Los funcionarios públicos, los cstadistas, los politicos, tienen de este condicionamiento externo una conciencia por lo menos tan aguda y clara como el que tienen de las limitaciones que les impone la situación política interna.

Sin embargo, si se tevisa lo que están escribiendo los economistas, sociólogos $y$ cientistas políticos en América Latina, el tema de la dependencia externa brilla por su ausencia. Pareciera que a la sociologia, a la economia y a la ciencia politica de posiguerra no les preocupara la cuestión. Y'o me pregunto si esc extraño fenómeno no es ya una primera manifestación de nuestra dependencia. El hechó es que no nos atrevemos a abordar el tema, ya sea por sus connotaciones y riesgos politicos, ya sea porque no ha siclo bendecido como parte de la temática aséptica y formalista que ahora sirve de patrón de referencia acadénico a nuestros especialistas en ciencias sociales. Para encontrar análisis serios del tema es preciso remontarse a las teorias clásicats del imperia-

\footnotetext{
Unx notable extejxión, que jajrec confirntar la regla. a el trabsjo tirnado Expartaco: "La crisis latinosmericana y un inarco cxterno", jublicado en Dearrollo Económico, juliodiciember, 1966, Juenos Airex.
} 
lismo, en su versión marxista- o en versiones mo marxistas ${ }^{3}$. Pero es evidente que esos teurias, claboradas, escritas y difundidas casi enteranente en las primeras tres decadas de este siglo, han quedado en gran medida rebasadas por los profundos cambios internos que han experimentado los países, asi como por las transformaciones radicales que han ocurrido en las relaciones entre cllos'.

Otro anteceden it relacionado con el tema de la dependencia, más reciente pero parcial, son los análisis criticos de la tcoría clásica del comercio internacional. Se trata de las ideas de Prebisch, Singer, Myrchal y otros, representadas institucionalmente en el trabajo de la CEPAl y más recientemente en el de la Sccretaria de la Conferencia Mundinl de Comercio y Desarrollo. Sin embargo, se trata sólo de un aspecto die la dependencia externa.

En contraste con la inopia absoluta en que se encuentra la investigación seria de este tema importantisimo en nuestros paises, la discusión pública y la controversia partidaria es abundantísima. Los enfoques dogmáticos y anecdóticos del problema de la dependencia externa están en todos los corrillos, incluso en los de aquellos mismos científicos sociales que rehusan ocuparse de él como tema de investigación. No es de extrañarse entonces que en la medida en que el cientifico social rehuye su responsabilidad de ofrecer a la comunidad información, análisis e interpretación seria y objetiva de un tema que le preocupa seriamente, campeen en el debate el extremismo, la parcialidad y la superficialidad.

De esta manera, la inversión privada extranjera, las donaciones, los créditos privados y oficiales y otras formas de transferencias de recursos de los países desarrollados a los subdesarrollados, constituyen para unos la "ayuda externa", "un desinteresado sacrificio que hacen los pueblos ricos para ayudar a sus hermanos pobres". Para los ouros, ese flujo de recursos externos representa la "nueva cara del imperialismo" a través del cual "los monopolios y carteles internacionales han encontrado nuevas formas de succionar la sangre de los

"Rosa Luxemburs: Die Akkumulation des Kapilals, Ein Beitrag wur ockonomischen Erklärung des Imperialismus; 1912.

Rudolf Hilicrding, Das Finan=kapital, 1910.

V. I. Ulyanov (N. Lenin). El imperialisma; fase superior del capótalismo (Edición original rusa en 1917).

N. I. Buklarin, Iforld Economy and Imperialism, 1918.

z. A. Hobson, Imperialisin, 1902.

J. A. Selnumpeter, "Zur Soziologic der Imperialisınen", Archiv für Sosialuissensehalt und Sozialpolitik; Vol. 46, 1919 (uraducción al inglés cn: J. A. Schumpeter, Jmperialism and Sorial Classrs, 1951).

Jacob Vincr, "International Finance and Balance of Power Diplonacy", 1880-1914; Soufh 1'testern Political Science Querterly, 1929.

Eugene Staley, Wiar and the Private Inzestor, 1935.

Villiam L. Langer, The Diplaman' of Imperialism, 1890-1302; 1935.

Lioncl Kobbins; The ceononic rauses of $\mathrm{H}^{\prime}$ ar, 1339.

E. Al. Winslow, The Pattern of Imperialism, 1948.

"Vese jor ejemplo, Jolun Strachry, El fin del Imperio, Mexico, 1902. 
pueblos oprimidos $y$ postergados para mantenerlos permanentemente en csa situación".

En lo que se refiere a los mecanismos de la dependencia polftica, los tratados y acuerclos internacionales en el campo cconómico, financicro y militar que conducen a la adopción de lineas determinadas de politica internacional e interna distintas que las que se habrían adoptado libremente, constituyen para unos "la defensa de lí libertad, la democracia y las tradiciones de la civilización cristiana occidental", mientras que para los otros se trata del "retorno del colonialismo y del imperialismo".

Menor, aunque creciente atención, ha recibido la transmisión masiva de actitudes, valores, formas de consumo y de vida, formas de expresión artística, de organización social, de investigación y de desarrollo tecnológico que viene acelerándose notablemente en años recientes. Para unos, todo esto es "el proceso de modernización y de racionalización que constituye la base y prerrequisito del desarrollo económico". Para los otros, se trata del "más funesto proceso de enajenación y alienación cultural, en que en aras de un bienestar que se confunde con el consumo de bienes materiales más o menos superfluos, se sacrifican los valores y tradiciones culturales propios".

Como toda clescripción esquemática, ésta tiene naturalmente también mu. cho de exageración y de caricatura, pero corresponde en esencia a la situación actual en materia de opiniones sobre las vinculaciones externas de nuestros países. Por cierto que ello difícilmente puede servir como base para iniciar una discusión seria y, en consecuencia, quisiera empezar desde otro lado.

Es fácil demostrar objetivamente que -junto a la aspiración a un mayor bienestar material- uno de los objetivos básicos de la politica de desarrollo es la afirmación de la nación. Si se revisan los programas de desarrollo, sobre todo en sus versiones políticas, de muchos países de la América Latina, se observará que se establece con frecuencia que uno de sus objetivos fundamentales es la autodeterminación, la independencia, una reducción en el grado de dependencia externa. Es más, si se analizan los programas y políticas de desarrollo e industrialización de América Latina - y de las otras zonas sub. desarrolladas del mundo también- se observará que uno de los elementos esenciales en que se apoyan casi siempre es justamente la aspiración de superar situaciones de dependencia externa. Voy a partir, por consiguiente, de la premisa de que ése es, en efecto, uno de los objetivos fundamentales que persigue la política de desarrollo económico en muchos países de la América Latina.

la pregunta que en seguida puede formularse es: ¿conduce cualquier poLitica de desarrollo hacia el cumplimiento de esc objetivu? De entrada se puede afirmar que no. Hay ejemplos excepcionales de politicas de desarrollo -entendidas en el sentido del crecimiento cconómico- que han sido muy exitosas descic este punto de vista unilateral, pcro que han significado no sólo la emigración de parte importante de la población, sino la desnacionalización de esos paises, su absorción dentro de otras culturas, clentro de otras civiliza- 


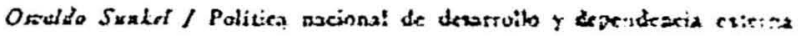

ciones, la formación de lo que alguien ha denominado an accradamente "pais sucursal". Creo que ese no es precisancnte el modelo icteal de desarrollo a que aspiran los latinoamericanos. De hecho, la opinión que entre nosotros existe cn relación a tal modelo, está revelando que uno de los objetivos de la polftica de desarrollo es, por el contrario, la afirmación de la personalidad nacional.

Es preciso, en consecuencia, examinar las policicas de desarrollo que sc vienen cumpliendo en la América Latina $y$ ver si en efecto conducen hacia el cumplimiento de uno de los objetivos esenciales del desarrollo nacional o si, por el contrario, están llevando hacia una ranyor dependencia del exterior.

Como se verá más adelante, el examen de las politicas convencionales de desarrollo revelará la existencia de tendencias contradictorias, unas de refuerzo de la situación de dependencia, otras que constitujen la base de un mayor grado de independencia en la politica de desarrollo. El anilisis de esas tendencias me lievará así a esbozar algunas estrategias y lineas de acción alternativas que, a mi juicio, permitirian inclinar la balanza en el sentido de reducir la dependencia, sin entrar en contradicción con otro de los objetivos fundamen. cales del desarrollo, la aceleración del ritmo de crecimiento económico.

Para no pecar de utópico e idealista, será preciso evaluar la viabilidad de tales proposiciones alternativas en la politica de desarrollo a la luz de la propia situación de dependencia en que actualmente nos encontramos. Todo esto, por supuesto, no es más que una primera tentativa de presentar el área de investigación de la dependencia externa -un área hasta ahora tabú para el análisis serio- en términos que hagan posible una discusión fructifera. Además, debo dejar muy en claro que lo que yoy a examinar a continuación son las tendencias de largo plazo que a mi juicio inlluyen sobre el fenómeno de la dependencia, y no los cambios circunstanciales derivados de situaciones político-partidarias más o menos perecederas.

\section{DEPENDENCIA EXTERNA Y CAMBIOS INTERNOS}

\section{LOS CAMBBIOS SOCIOPOLÍTICOS INTERNOS Y SU SIGNIFICADO}

Para comprender mejor en qué consiste en su esencia el fenómeno de la dependencia en la América Latina, creo que conviene cornenzar por un breve examen de ha evolución socioeconómica de la Améría Latina en rasgos muy generales y en términos de algunos periodos signilicativos. En efecto, Ja actual estructura economica, social $c$ institucional de nuestros paises presenta características cuyos origenes se remontan a distintos periodos formativos claves de nucstra historia.

Antes de mediados del siglo $x \mathrm{x}$ se consolida en la América Latina la estructura rural tradicional, esa estructura rural que, según se viene insistiendo 
desde hace años en muchos tomos y por muchos jados, cs necesario cambiar a. través de los procesos de relorma agraria.

Entre fines del siglo xix y la decada de 1930 surgió en la America Latina lo que todavia es hoy la estructura característica de su comercio de exportación e imporación $)^{t}$ de sus vinculaciones financicras con los países industrializados. Esa es la época en que la major parte de los pąises de la América Latina desarrollaron, sobre la base de la inversión cxuranjera, aquella actividad productora de materias primas de exportación que hoy caracteriza su comercio exterio

Finalmente, desde la década de 1930 en adelante, y sobre todo en los países mayores del cono sur $\mathrm{y}$ en México, se superpone a esas dos formaciones históricas previas, una nueva. Es la eta pa de la industrialización, de un proceso más acelerado de urbanización y del surgimiento de la politica social: los sistemas de previsión social, las politicas de vivienda, de salud y de educación. Es también - puesto que todos estos fenómenos impusieron grandes tareas al sector público- la etapa en que el Estado se amplía considerablemente y adquiere. nuevas funciones.

Es obvio que las transformaciones sucesivas experimentadas por la estructura económica de nuestros países en estos tres periodos tuvieron cada una influencias sobre las formaciones históricas previas. Pero lo que más poderosamente llama la atención es más bien el fenómeno contrario, es decir, la porfiada resistencia de las estructuras agrarias y del comercio exterior a las influencias dinámicas sucesivas de la expansión de este último sector, primero; y luego al impacto de la industrialización. Es como si el desarrollo de nuestras. sociedades se hubiera dado más por agregación sucesiva de nuevos sectores que por la transformación y evolución interna de sus formaciones sociales originarias.

En todo caso, la creciente diversificación de la sociedad latinoamericana. en los periodos indicados tuvo efectos importantes en la estructura social y económica. En términos de la estructura social, se pasó de una organización social bipolar muy simple - una situación de oligarquia dominante y de masa rural que no era ni siquiera cúerpo politico-a una diferenciación social mucho más acentuada, consecuencia de la formación de actividades exportadoras modernas, del proceso de industrialización, del crecimiento de las ciudades, de la ampliación del aparato estatal, del avance de la educación, etc. Estos fenómenos han dido lugar a una complejidad mayor en la estructura social, reduciendo el papel protagónico de la oligarquia tradicional, incorporando al menos parcialnente a la masa rural y urbana en algunos paiscs al proceso de participación politica, e injertando en medio de estos dos cxtremos que caracterizaban a la situación social de smérica Latina una variada gama de capas, grupos, clases y estamentos sociales, particulanuente urbanos: el cmpresario industrial, los profesionales y téenicos, los semidores de euello blanco y curbata, 
tanto del sector público como del sector privado, los grupos obreros organizados, el estudiantado, etco.

En la medida en que estos diferentes grupos medios y la masa influyen crecientemente en el proceso político, se produce una tendencia, que a veces sólo está latente, pero que en muchos casos se manifiesta claramente, hacia una mayor representatividad de la comuniclad en el Estado, hacia un mayor grado de participación de grupos cada rez más amplios de la nación én la formación y en la conducta de los asuntos del Estado. Si es rerdadero que esa tendencia se ha venido manifestando y que tiende necesariamente a ocurrir a largo plazo con el propio proceso de desarrollo, entonces es posible que en la diferenciación de la estructura social y en la mayor participación de la comunidad nacional en el proceso político a que elio debiera dar lugar, pudieran estar las raices de una manifestación más amplia y decidida del interés nacional y colectivo, y, por consiguiente, la posibilidad de alianzas politicas de grupos determinados de la clase media, con la gran masa rural y urbana.

Este tipo de alianzas, que se han dado en ciertos casos en América Latina, tienen evidentemente un contenido - al menos potencial- de representación de intereses y objetivos nacionales y colectivos mucho mayor y completamente distinto de lo que ocurría en el caso de las sociedades bipolares tradicionales. De hecho, el nacionalismo, el desarrollo y la organización y participación populares vendrian a ser los pilares ideológicos de tales alianzas. Desde este punto de vista parecieran, por consiguiente, presentarse condiciones, por lo menos potenciales, para que una política de desarrollo nacional pueda traducirse en programas, en estrategias de acción y en movimientos políticos concretos en algunos de nuestros paises.

Todo esto requiere, sin embargo, que determinados grupos medios estén dispuestos a asumir el liderazgo de la masa marginada urbana y rural en términos de su organización e integración en el proceso político y en la vida económica, social y cultural de la nación. Como un programa de esta naturaleza implica necesariamente una redistribución del ingreso y la riquera, una transferencia del poder político y un reordenamiento de las oportunidades sociales, así como un considerable esfuerzo de ahorro y movilización de recursos, los grupos medios que disfrutan de situaciones económicas, sociales y políticas de relativo privilegio se opondrán naturalmente a semejante política. Esta interesará, en cambio, a los grupos medios que no han podido realizarse en el proceso de desarrollo y que no ven en la orientación y escasa intensidad que éste lleva, perspectivas de realización futura. En las condiciones de paises en que la industrialización por sustitución de importaciones se comienza a debilitar, esta frustración se presenta especialmente entre algunos grupos de profesionales y técnicos, en los cuadros técnicos de la burocracia pública y privada, en los empresarios nacionales desplazidos por la empresa privada

svése de Fernando It. Cardoso y Jose Luis Rryna, Industrialieación, estructura ocupacional

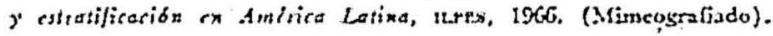




\section{ESTLEIOS T N TER Y A C I O NALES}

extranjera y en las instituciones que reaccionan más bien en función del interés colectivo y de largo plazo que en acención a los objetivos particulares inmediatos. Trittase aquí de los intelectuales y la juvencud y de instituciones como la iglesia y las fuerzas amadas.

Con respecto a esta última institución, su papel potencialmente "nasserista" y reformador es probable que en América Latina se encuentre frustrado en la medida en que ha sido incorporada funcionalmente a la guerra fría a través de la doctrina de la frontera ideológica, doctrina que se presta maravillosamente para confundir deliberada o inconscientemente un programa nacional de transformaciones búsicas con un proceso subversivo respecto de la potencia hegemónica y de los grupos dominantes internos; es asl un poderoso instrumento puesto en manos de los intereses internos y externos resistentes al cambio y que puede ser invocado por éstos en momentos de peligro.

Otro fenómeno que puede restar fuerza a las posibilidades de que ciertos grupos medios asuman el liderazgo de una politica nacional de desarrollo, reside en el grado de enajenación cultural de estos grupos, en la intensidad de sus aspiraciones inmediatas de asimilar formas de vida y de consumo "modernas" y en la medida en que estas aspiraciones se pueden realizar para esos grupos a través de la asociación con el capital privado extranjero y con otras agencias externas de diverso tipo. Por otra parte, en la medida en que estos grupos medios sean víctimas de la propaganda politica -que ha llegado ya al extremo de envenenar incluso la literatura, el cine y la televisión infantiles- y acepten la doctrina de la guerra fría y de la frontera ideológica, podrán ser fácilmente atemorizados y llevados a rechazar una politica de desarrollo nacional.

Como puede apreciarse, el análisis anterior revela tendencias contradictorias en cuanto a la posibilidad de llevar a cabo el desarrollo nacional. Por una parte, vienen ocurriendo cambios básicos en la estructura social, con sus fenómenos de masificación, de crecimiento y diferenciación de los grupos medios y de ampliación del proceso y mecanismos de la participación política. Por la otra, existen grupos de interés y sectores asociados con actividades externas, así como tendencias a la enajenación cultural e ideológica, particularmente en los grupos medios, al menos en aquéllos que cumplen sus aspiraciones por medio del actual proceso de desarrollo. Por consiguiente, si este análisis es correcto, no pareciera haber aqui leyes o tendencias históricas inevitables en uno u otro sentido, sino contradicciones que abren posibilidades de opción y de acción alternativa, en función de los cambios que pueden sufrir las variables exógenas y de la manipulación de las variables cule están sujetas a influencia directa.

En otras palabras, dadas ciertas circunstancias externas c internas, y un conocimiento analiticamente adecuado del proceso de cambio, pareciera ser conccbible la formulación y aplicación de una política de desarrollo nacional. A falta de tal comprensión y de un programa concreto de desarrollo aacional, 
no se sabrix cómo llevar a cabo dicha politica, atun si se presentara la oportu. nidad propicia; $y$ lo que es peor, fni siquiera se percibiria la prescncia del momento oportuno: Mi opinión personalisima es que, a estas alturas de auestro desarrollo, es en esta falta de esfuerzo intelectual y cientifico para comprender nuestra realidad histórica y nuestras posibilidades autónomas de acción, así como en nuestra falta de imaginación para inventar soluciones a nuestros problemas, donde está, más que en ninguna otra parte, el origen de nuestra incapacidad para atenuar, modificar y finalmente superar la situación de dependencia.

La formulación de una estrategia de desarrollo macional exige por consiguiente un dinguóstico preciso de los mecanismos de la dependencia en todos sus planos: económico, politico, militar, cultural. En esta oportunidad me referiré únicamente a ciertos aspectos económicos, sin que ello quiera decir que los otros no sean de importancia; ya han quedaclo sugeridos algunos elementos claves de la dependencia en aquellos planos.

\section{EL DESARROLLO X LOS MECANISNIOS DE LA DEPEADEACIA ECONÓNTICA}

La evolución histórica de nuestras economins a que he hecho referencia antes ha dejado como resabio algunos rasgos característicos en nuestra estructura económica, que es de importancia destacar desde el punto de vista de la consideración del problema de la dependencia y de una política nacional de desarrollo.

En primer lugar, se conserva todavía en parte importante una estructura agraria tradicional que ba limitado seriamente la modernización y tecnificación de la actividad productiva rural. Esta ha sido, en consecuencia, incapaz para responder con eficacia a los requerimientos de una demanda de productos agropecuarios estimulada poderosamente por el crecimiento de la población y de los ingresos urbanos así como por el desarrollo de la propia industria, que al menos en sus etapas iniciales se basa en gran medida en las materias primas agricolas. Entre otras consecuencias gravest, esta situación ha contribuido a agudizar los persistentes problemas de balanza de pagos de nuestras economías, ya sea porque se han reducido las exportaciones o porque han aumentado considerablemente las importaciones agropecuarias.

En segundo lugar, hemos heredado una estructura del comercio exterior que en abierto desafio a declaraciones de política que se vienen repitiendo desde hace por lo menos veinte o veinticinco años, sigue siendo una estructura especializada de monoexportación. En efecto, desde la segunda guerra mundial se

'La signifieación de este fenósneno desde el punto de rixta de las presiones infacionarias $y$ de sus efectos sobre la distribución de los ingreses $\gamma$ la expansión industrial, pucde verse en mis uabajos: "Laz inflación chilena: un enloque hetcrodoxo". El Trimestre Feconómica, Ni 100, octubre-diciembre, 1958, Mf́xico; y "El fracaso de las politicas de estabilización en el contexto del proseso de dasrollo Latincameriano", El Trimatre Económieo, No 120, octubrcdiciembre 19rỉ, México. 
viene insistiendo en la necesidad de la diversificación de las exportaciones y de aumentar el grado de elaboración de las materias primas, pero las cifras revelan que en la mayoria de los paises de América Latina de hecho ha aumentado ligeramente el grado de concentración de nuestras exportaciones en muy pocos productosi.

En tercer lugar, la ctapa de la industrialización, no ha producido tampoco todos los beneficios que de este proceso se esperaban. En particular, ha dejado de cumplir uno de los objetivos básicos que se le atribuia: la reducción de la dependencia externa. En efecto, si bien la industrialización ha permitido reducir la proporción del gasto en importaciones con respecto a la actividad económica interna - el coeficiente de importación-, por otra parte, ha significado un cambio de gran trascendencia en la estructura de las importaciones. Si décadas atrás una gran proporción de nuestro gasto de divisas se dedicaba a la compra de bienes de consumo no esenciales, hoy se importan -al menos ex las economias más industrializadas de la región-casi sólo bienes esenciales: máquinas, equipos y herramientas para mantener en funcionamiento y para ampliat la capacidad productiva; materias primas y productos intermedios para asegurar un nivel normal de actividad económica, e incluso, con frecuencia, alimentos básicos para maritener el consumo popular. Es decir, se ba llegado a una situación de vulnerabilidad externa en que cualquier alteración en los precios exteriores, cualquier problema de financiamiento externo causa serias dificultades, ya sea por la escasez consiguiente y el aumento de precios de los productos de consumo esenciales, ya sea por las necesarias restricciones a la importación de materias primas y su efecto sobre el normal desarrollo de la actividad fabril, ya sea por la postergación de la importación de maquinaria y equipos y su influencia sobre la capacidad productiva.

Este curioso resultado es en gran medida consecuencia de la forma en que se ha venido llevando a cabo la política de industrialización en la América Latina: el llamado proceso de sustitución de importaciones. Ante situaciones de penuria de divisas se limitó la importación de los bienes de consumo. Pero como no se limitó la demanda interna por esos bienes ni se impidió la importación de las máquinas y materiales necesarios para producirlos, se crearon las condiciones para empezar a producirlos dentro del país. La protección favoreció a la empresa nacional, pero las tradicionales vinculaciones cxternas, en una especic de salto mortal, superaron la tarifa proteccionista y la política de prohibición de importaciones, $y$ lejos de desaparecer, se acentuaron. Los biencs que antes se importaban pasaron, en electo, a producirse en alguna medida internamente. Pero para ello no sólo era necesario importar los equipos y máquimas correspondienies y además parte considerable de los clememos que entran en su claboración, sino además incurrir en costos financieros externos que han llegado a constituir en varios paises una carga abruma-

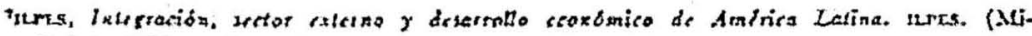
messtafiado), 19ck, cuadro $11-4$. 
dora. Esto se debe no sólo a que buena parte de esa industria interna es de propiedad extranjern -subsidiarias de grandes empresas multinacionales - y a que hay muchos productos cuja elaboración se lleva a cabo bajo licencia o contratos de asistencia técrica externos por los cuales se paga diversas [ormas de remuneración, sino también al hecho de que para acelerar la propia industrialización $y$ las inversiones de infracstructura se recurrió en forma importante al financiamiento público y p ivado externo. En atención a estas caracteristicas, el proceso de sustitución de importaciones ha venido a redundar, por una partc, en una gran vulnerabilidad de nuestra balanza de pagos y, por la otra, en compromisos financicros externos que en algunos paises de la América Latina representan una proporción considerable de la disponibilidad de divisas.

Finalmente, otro de los rasgos caracteristicos heredados en esta etapa de industrialización, es la constitución de un Estado muy amplio y actuante, que a mi juicio, ha cumplido tres funciones básicas durante el periodo de 1930 hasta el presente. Apoyándose en forma creciente en la captación de parte considerable de los recursos financieros de la actividad exportadora, que era el único sector de la economía donde en virtud de su elevada productividad se generaba un excedente de recursos abundante, el Estado pasó a desempeñar tres nuevas funciones principales: de mecanismo financiero, para trasladar recursos financieros y subsidiar el desarrollo de la actividad industrial privada, generalmente a través de instituciones de fomento; de mecanismo de redistribución de ingresos, mediante la destinación de recursos para el desarrollo de la política social a través de la seguridad y previsión social y de la ampliación de la educación, de la vivienda y de la salud; de mecanismo de inversión estatal, a fin de adecuar y ampliar la infraestructura económica de los transportes, de las comunicaciones y la energía, e incluso para crear empresas industriales básicas, generalmente en la siderurgia. Como puede apreciarse, el proceso de industrialización y desarrollo iniciado en la década de 1930 en los países ahora más industrializados de América Latina -y en los otros más recientemente- se apoyó en un pilar fundamental, el sector público. Este pasó a cumplir después de la gran crisis dos funciones estratégicas de la política de desarrollo: la captación de recursos de las actividades de clevada productividad de una parte y su reasignación para promover el desarrollo industrial y el desarrollo social, por la otra.

En esta nueva función el Estado ha venido enfrentando dos tendencias contrarias que se agudizan cada vez más. Por un lado, una sed insaciable de captación de recursos a fin de usarlos en los programas de industrialización, de infraestructura, $y$ sobre todo en el área de los servicios sociales. Por el otro lado, la gallina de los hucros de oro - el sector cxterno- se ha quedado relativamente estancado, principalmente a raiz de políticas y tendencias econónicas y tecnológicas cuyo origen está en las cconomias industriales y sobre las cuales los paises de America Latima han tenido escasa innuencia. En consecuencia, la principal y uadicional base tributaria de nuestros gobiernos, una 
vex alcanzado cierto limite de tributación, dejó de aumentar al mismo ritmo que las necesidades rápidamente crecientes del sector público. Los problemas polfticos y administrativos para cxtender rípicla y eficazmente el sistema tributario nacional y aquéllos derivatos de la propia estructura cconómica, han determinado de este modo una tendencia sistemftica y permanente al déficit en el sector público. Dada además la inestabilielad de las recaudaciones provenientes del sector externo, la tendencia al. defficit se agucliza cuando los mercados externos se deprimen y se atenúa cuando se encuentran en situación boyante, en tanto que las nucvis funciones que el estado ha iclo adquiriendo han significado nuevos compromisos financieros permanentes y con una dinámica propia.

Como consecuencia de los cuatro procesos característicos que se acaban de esbozar ${ }^{8}$ - la insuficiencia dinámica de la agricultura tradicional, la estructura del comercio exterior, el tipo de industrialización $y$ la función que viene cumpliendo el Estado- nuestros países son, desde el punto de vista de la estructura y funcionamiento de su economia, enteramente dependientes. Lo grave, y que no siempre se reconoce, es que esta extrema dependencia de nuestras economías está arraigada en la vulnerabilidad y tenclencia deficitaria del comercio exterior; en el hecho de que el tipo de industrialización y la forma de explotación del sector exportador no ha permitido a nuestros paises -salvo excepciones- adquirir capacidad propia y acumulativa de adaptación y de creación tecnológica; en que una parte importante y probablemente creciente de la industria y de la actividad exportadora es de propiedad extranjera o depende de licencias o de asistencia técnica externa, todo lo cual pesa fuertemente en la disponibilidad de divisas; en que tanto el sector fiscal como las cuentas exteriores tienden persistentemente -salvo ocasiones excepcionales- al déficit, lo que lleva al financiamiento externo. En ciertas condiciones, este financiamiento externo puede llegar a significar la acumulación de deudas exteriores tan considerables y de una tal estructura de vencimientos, que su propio servicio obliga a recurrir -en auténtico cĺrculo vicioso- a financiamiento externo adicional' ${ }^{\natural}$. En este aspecto -la necesidad imperiosa e inaplazable de obtencr financiamiento externo- es donde se resume en último término la situación de dependencia; este es el punto álgido del mecanismo de la dependencia

De todo lo que llevo expuesto hasta ahora se deduce que si bien la estructura social se ha diferenciado y los grupos medios y la masa han adquirido cada vez más representatividad y participación en el funcionamiento político de los paises, exigiendo una atención creciente a los intereses generales de la nación, no es menos cierto que se ha creado una situación de finan.

spara un análixis mis completo puede verse mi articulo: "El trasfondo ostructural de los problemas del desatrollo Lutinoamezicano"; El Trimejler Económico, Mćxico, cnero-marzo, 1967.

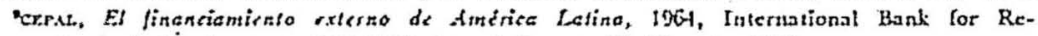
construction and Developutent, I955-15S6 Anxual Regors, Wiastington, 1965. 


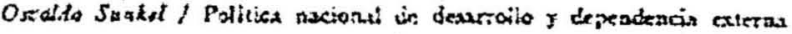

ciamiento externo extremadamente delicada que -independicntemente de otras formas de dependencia - coloca a nuestros paises cn una pasiciön particularmente endeble frente a cualquier presión que se quicra ejercer sobre ellos - no sólo, cridentemente, en lo que se refiere a la politica de desarrollo.

\section{EL DESARROLLO NACIONAL}

\section{NATUQULETA DEL DESARROLLO NAGJONAL}

Si el análisis anterior es certero, no queda más que indagar las posibilidades de reorientar la politica de desarrollo tradicional, de manera tal que se puedan ir reduciendo esas formas de dependencia que están enraizadas en la propia estructura y funcionamiento de nuestras economias, tendencias que se han venido agudizando $y$ se han traducido concretamente en una dependencia financiera extrema. En otras palabras, esto implica reconocer que la independencia económica no puede ser lá consecuencia mágica de un acto político heroico, sino el fruto a mediano o largo plazo-depende en cada caso- de la construcción de una economía nacional eficiente, flexible y capaz de generar un amplio y rápidamente creciente cxcedente de recursos de inversión. Esta realidad, en su sentido técnico-económico, no es, por cierto, esencialmente diferente de la que enfrentan los paises subdesarrollados que se esfuerzan por lograr el desarrollo nacional por la via socialista. Sin embargo, mientras en estos casos la aspiración al desarrollo nacional es parte esencial de la propia definición y base social del régimen politico -así lo confirman las contradicciones y el "deshielo" en las relaciones entre los paises del bloque socialista y su potencia hegemónica en la medida en que aquéllos se han desarrollado nacionalmente- en los paises subdesarrollados del área capitalista la propia posibilidad política del desarrollo nacional se plantea como una interrogante previa y decisiva. Esta interrogante crucial es la que nos corresponde dilucidar, puesto que de su respuesta depencierá si el objetivo de construir una nación independiente es al fin $y$ al cabo un objetivo viable y posible o si es puro idealismo. Esta cuestión me parece básica y pertinente porque creo que la alternativa que dogmáticamente se nos quiere imponer de uno y otro campo ideológico - revolución socialista o "paissucursal"- no es una alternativa real.

Una de las posibilidades, la revolución socialista radical, me parece un acontecimiento histórico muy poco probable en el futuro próximo de Ia América Latina, debido a una combinación de circunstancias externas e internas de orden geográfico, militar, político y económico. Podrá haber erupciones y hasta gucrillas bastante extendidas en algunos casos, pero ello seguramente tenderá a reforzar el stalus quo y la dependencia externa y no lo contrario. Por otra parte, el modelo del "pais-sucursal" tampoco me parece viable a largo plazo y para el conjunto de paises de América Latina. Aparte 
de los elementos negativos de orden general citados anteriormente, la cxperiencia de la región en las últimas dos décadas parece suggerïr: a) que este modelo requjere una masa de recursos externos que al mundo industrializado -particularmente a la empresa privada- no le interesa translerir a la periferia; b) que el modelo de industrialización por sustitución de importaciones tiende, despues de un periodo de gran dinamismo, $e$ incluso en los países majores de la región, al estancamiento, y c) que no obstante los esfuerzos realizados en materia de industrialización y politicas sociales, se viene observando que una masa creciente de la población va quedando al margen del sistema socioeconómico, constituyendo amplios sectores que no logran integrarse en la vida econónica, social, cultural y política de nuestros paises ${ }^{10}$.

En consecuencia, mientras el camino rerolucionario ha quedado impedido por ahora, persistir en el "desarrollismo" de las últimas décadas -cuando su etapa positiva parece ya haberse cumplido- conducirá a la frustración. Debido a ello estoy convencido que aquellas alternativas son falsas; la verdadera, a mi juicio, es el desarrollo nacional.

Para evitar confusiones debo reiterar a estas alturas lo que entiendo por desarrollo pacional. No se trata evidentemente del nacionalismo autárquico, xenófobo, racista, fascista e imperialista que en europeos y norteamericanos evoca el término "nacionalismo". Ese es el "nacionalismo desarrollado". El nacionalismo de los países subdesarrollados, conviene recordarlo, surgió o se acentuó en los paises atrasados como consecuencia, en parte, de la lucha contra aquellas prácticas, tanto al aportar su cuota de esfuerzo a las potencias aliadas durante la Segunda Guerra Mundia\}, como al resistir y enfrentar similares prácticas que -bajo un falso internacionalismo- esas mismas potencias practicaban en sus colonias y dependencias. El nacionalismo del desarrollo es un esfuerzo de afirmación nacional, una aspiración a la autodeterminación $y$ a la soberania, un deseo de participar del dis[rute y la creación de la cultura y de la ciencia modernas y universales, el anhelo de lograr la libertad, la democracia, la igualdad de oportunidades y el bienestar de que disfrutan en mayor o menor medida los paises más industrializadosil.

Ahora bien, como ya quedó indicado, en la medida en que el proceso de desarrollo avanza, major es la participación sociopolítica de grupos y clases sociales, cada vez más representativas de la nación, de sus tradiciones, cultura, valores, instituciones e historia. Estos, y no otros, son los ingredientes con que la nación cuenta para crear y llevar a cabo su propio proceso de desarrollo y realización nacional. Sustituirlos pox ingredientes importados

m'er, entre otros: Pablo Goazilicz Casanova: "Soxiedad plunal y desarrollo: el caso. de

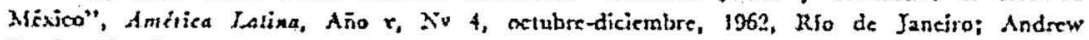
Frank: "La inestabilidad urtasa en Amérien Latina"; Chadernas Amerirenor, Mérico, enerofelarero, 1966; Cetso Furado; "Drsarrollo y calanramiento en Amxisica Latina"; Desarrollo

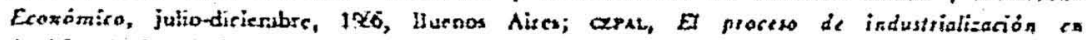
Arariva Latina. Zf́rico, ITK6.

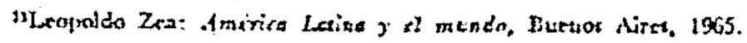


es destruir la nación en su escncia - convertimos en parias tanto de nuestra propia historia como de la de las sociedades avanzadas. Lo que se requiere es una tarea de modernización imitativa y creadona a la vez, basada en una selección deliberada y consciente de lo que hay de auténticamente universal en la cultura y civilización modernas y en una gran imaginación capaz de construir con estos elementos las politicas, las instituciones, las idcologias $y$ los demás instrumentos del desarrollo nacional12. Pero no cabe duda que todo esto se manifestará necesariamente en la ruptura, rechazo o reforma de aquellas circunstancias y situaciones internas y extemas que interfieran o impidan la realización de la democracia, ja jibertad, el bienestar y la igualdad de oportunidades, asi como la libre elección del camino y los medios de la politica de desarrollo nacional. Sería fácil confundir estas manifestaciones sanas y positivas del nacıonalismo con la xenofobia, el autarquismo y la soberbia patriotera. Pero no se trata de eso, se trata de reconocer en forma realista que la dependencia es una característica estructuralmente inherente al subdèsarrollo y que el desarrollo -para serlo auténticamente- debe tender a reemplazax la dependencia por la interdependencia, entendiendo por esto una situación tal que la nación que enfrente presiones o limitaciones externas en su desarrollo pueda por sí misma crear o escoger formas alternativas de responder a esas situaciones.

\section{EL PAPEL DE LA INTEGRACIÓN LATINOAMIERIGANA}

Después de todo lo que se ha dicho surge, sin embargo, una duda fundamental, ¿es acaso posible o viable en todos los países de la América Latina una política nacional de desarrollo? En términos aún más crudos: dlos países de la región son efectivamente naciones viables en el sentido económico. técnico? Hay quien sostiene que no, y con razones poderosas. El desarrollo parece exigir en esta era nuclear, o de la Segunda Revolución Industrial, mercados vastísimos, masas ingentes de recursos destinados a la investigación científica, una mano de obra de elevadísimas calificaciones técnicas, etc., condiciones estas que pocos - si acaso alguno- de los países de América Latina pueden cumplir antes de ser incorporados como áreas coloniales en espacios cconómicos mayores ${ }^{13}$.

Ante la posibilidad de una perspectiva semejante -que no por visionaria carece de verosimilitud- la necesidad de la integración latinoamericana adquiere su verdactera dimensión y razón de ser. La integración puede ser, en efecto, un instrumento básico de la realización nacional de América Latina. pero también puede serlo para la "sucursalización" acelerada de la región.

1=Jose Medina Echavarifa: Filosofle del desarsollo; Siglo xxi y Editorial Universitaria, 1967. Crlso Furtado: "Hacia una ideologia del desarrollo"; E Trimes/re Econbmieo, No 131, 1966.

دHelio Jaguaribe: Descatolsimetlo Económico . Desrncolsimento Poltico, Rio de Janeiro, 1962. Tambies: Political Aodels and S'ational Dezelogment in Latin Ameriea. Tralszo presentado a! Ia Congreso Interanericano de Planificaciön, Caracas, cetubre, 1966. 


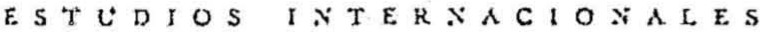

Las condiciones y la politica actuales de la integración parecerian favo. recer más bien esta última tendencia, ya que son en principio las cmpresas subsidiarias de una empresa matriz multinacional extralatinoamericana, localizadas en diversos paises de la región, las que en mejores condiciones se encuentran para planificar sus activịlades con miras a la explotación óptima de una zona de libre comercio, y a desplazar de la misma -y aun de los mercados internos- a las empresas nacionales. Igual cosa ocurriria con respecto a las.industrias nuevas de gran densidad de capital y complejidad tecnológica que se instalarian en atención a la existencia de una zona de libre comercio.

Para que la integración cumpla los propósitos de realización nacional antes indicados, los caminos a seguir tienen que ser evidentemente diversos a los indicados mús arriba. Pero mientras éstos son los que tienden naturalmente a seguirse, y ya se están poniendo en práctica, una integración conducente al objetivo de la realización nacional latinoamericana y a una menor dependencia externa de la región en su conjunto y de cada país en particular, requiere de iniciativas multinacionales para desarrollar -al menos en una primera etapa -sectores productivos básicos- siderurgia, petroquímica, electrónica, mecánica, etc. -bajo control latinoamericano. Esto parece ser una condición sine qua non para que América Latina pueda adquirir: a) capacidad propia de creación tecnológica; b) actividades productivas en escalas considerables, con alta y creciente productividad; c) sectores capaces de generar excedentes sustanciales de recursos para la expansión de la capacidad productiva, y d) una estructura productiva que le permita dinamizar sus exportaciones - diversificándolas con productos manufacturados- y atenuar el dinamismo de sus importaciones, sustituyendo los bienes de producción. En otras palabras, los esfuerzos inmediatos de la integración debieran centrarse en la concertación de acuerdos productivos particularmente en relación con las ampliaciones de capacidad productiva en el sector de los bienes básicos de producción, y a través de empresas, consorcios o trusts estatales o mixtós multinacionales latinoamericanos; es decir, en la planificación multinacional de las actividades industriales básicas existentes y adicionales ${ }^{14}$.

Los esfuerzos actuales en materia de integración se concentran en cambio en la liberalización del comercio intralatinoamericano. En este sentido apenas st se ha logrado restablecer la importancia relativa que ese comercio ya tuvo con respecto al comercio exterior total de América Latina en épocas anteriores: los perioclos bélicos y el período de los convenios bilaterales de mediados de la década de 1950 . De hecho, el comercio interlatinoamericano apenas logró superar los niveles absolutos de 1955 recién en 1964. Además, tlegado a los niveles de los últimos años, las concesiones se han hecho cada rez menos significativas

\footnotetext{
"Baneo Interamericano de Desarrollo; Fartures para la inlegreciön Latinoamericana; Mréxico, 1965. Ver especialmente pp. 12-70 y apéndiecs B (Coordinación de has politicas de inversiones, por Ado Ferrer) y $F$ (Coordinación de las politicas uacionales, por Helio Jaguaribe).
} 
y más dificiles, y el crecimiento del infercambio $x$ h: zeenuadols: en todo caso este incremento del intercambin h.a sido esencialmente en proceluctos tradicionales, casi enteramente entre paise. limitrofes y sin significación mayor desde el punto de vista de su contribucion al proceso de destrollo: dinamiazion del crecimiento industrial, aprovechamiento de capacidad ociosa, ventajas de las economfas de escala, especialización productiva, steperación del estrangula. miento externo, etc.

Todo lo anterior se .efiere particularmente al proceso de integración en el área de la alalc y no al Mercado Común Centroamericano, que difiere justamente en su acentis en la planificación conjunta de la capacidad productiva y de la infraestructura adicional, y en donde el proceso tradicional de sustitución de importaciones se está dando en el contexto del mercado integrado, por lo que el comercio crece rápidamente con cambios importantes en la estructura productiva. Pero aqui se tropenrí también tarde o temprano con las dificultades señaladas más atrás con respecto al proceso de sustitución de importaciones en los países más avanzados y majores de la región, ya que ese proceso se está dảndo igualmente sobre la base de la producción de bienes de consumo y de una participación indiscriminada del capital privado extranjero. Por otra parte, el mexcado centroamericano integrado es seguramente muy limitado para servir de base a una actividad manufacturera competitiva en el mercado mundial y capaz de dinamizar integralmente esas economias.

Las observaciones anteriores sobre el problema de la integración pecan sin duda de superficiales y parciales. Pero mi intención no es la de entrar a fondo en el estudio de este complejo tema, sino la de ilustrar hasta qué punto una politica latinoamericana de desarrollo nacional implica la necesidad de adoptar estrategias completamente diversas de las que con tanto empeño, pero limitado éxito se vienen persiguiendo actualmente.

\section{La Superacióx del Modelo "Cevtro-PertFeria"}

Tal como en el área de la integración económica, Ia política nacional de desarrollo también exige reajustes fundamentales en la estrategia interna del desarrollo. No estoy en condiciones de hacer a este respecto un planteamiento exhaustivo, que por lo demas no podría ser general, puesto que deben tomarse muy en cuenta las circunstancias de cada pais. De nuevo me roy a referir solamente a algunos aspectos esenciales y respecto de los cuales creo que una reorientación es posible y significativa.

En páginas anteriores sugeri una explicación de la naturaleza estructural del problemn de la dependencia, que se resumfa en la tendencia deficitaria

WMliguel S. Wionezek, "Apreciaciones sobre el desastre de Montevideo", Comescio Erterior; diciembre de IGEE (Revists del Banco Nacional de Comercio Exterior de Mléxico). 


\section{ESTUDIOS INTER N A I I X A L E S}

de la balanza de pagos y del presupuesto y en cl consizutente problema del financiamiento externo. Desde hace muchos años ha sido grande en América Latina la preocupación por obtener cambios en los módulos de nuestro comercio exterior. En años recientes, y como consecuencia del período de dete. rioro de la relación de intercambio de 195.t a 1962, esos esfuerzos se han renovado $\mathrm{y}$ han conducido a la creación de un orgąnismo mundial dedicado a este problema: la Conferencia de las Naciones Unidas para el Comercio y Desarrollo. Los planteamientos de los paises en desarrollo se refieren principalmente a: acceso de los productos manufacturados a los mercados de los paises industriales, eliminación de impuestos internos, tarifas y otras trabas a la importación de los productos básicos que exporta la periferia, convenios de estabilización de precios de los productos básicos o mecanismos de compensación financiera, mayor grado de elaboración de los productos básicos en los paises subdesarrollados, términos menos onerosos en el financiamiento externo, mayores inversiones privadas extranjeras, mayor ayuda financiera y téc-

ca externa, etc

Nio obstante. Os denodados esfuerzos que se han dedicado y continúan dedicándose a la obtención de éstos y similares objetivos, hay que reconocer que han sido hasta ahora casi enteramente infructuosos $\mathrm{y}$ que las probabilidades de éxito futuro son escasisimas. La raíz fundamental de esta situación se encuentra, a mi juicio, en que todos los objetiros que se persiguen representan algún sacrificio para los paises industriales. No creo que vayan a realizarlos a cambio de nada, sobre todo, teniendo en cuenta que las medidas correspondientes tienen importantes repercusiones económicas y políticas internas sobre determinados intereses, grupos o regiones. Incluso la ajuda externa pública, en donde el motivo moral y de solidaridad internacional podría tener peso, corresponde de hecho en la mayoría de los casos al interés económico o cultural, y sobre todo político, del pais que ofrece la ajuda. Y' mientras mayor la ayuda, mayor la tentación y posibilidad de usarla en la obtención de fines propiosio.

Pero aun cuando aquellas medidas propucstas con tanta insistencia por los paises subdesarrollados alcanzaran éxito, el resultado sólo permitiría bacer más viable - dentro de su precariedad y seguramente por un tiempo limitado- el modelo tradicional de "centro-periferia". Las diversas estimaciones de la amplitud de la futura "brecha de comercio", aún en sus hipótesis más optimistas -que suponen diversos grados de exito en las politicas indicadas--, lo confirman.

La cuestión fundamental que plantea una policica nacional de desarrollo no es sin embargo lograr la viabilidad del tradicional modelo "centro-peri-

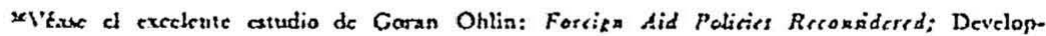
ment Crnte of the Organization for Economic Cooperation and Development, Paris, 1966. Adezis, M. Kalecti e 1. Sach: "rurmes de La equdx exterior: ta ansilisis econbrnico";

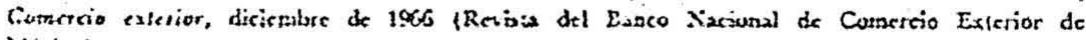
Mrivis). 
feria", sino por el contrario, superarlo definitivamente. $X$ para ello me parece que lo central radica en lograr cambios en la estructura productiva interna en los paises subdesarrollados, así como cambios en la naturnleza de sus vinculaciones externas. Si se logra esto, entonces las concesiones, ventajas y ayuda de los paises desarrollados podrán dar su verdadero fruto, pues contribuirán a J.evar a cabo la política nacional de desarrollo. Faltando el requisito sine qua non de los cambios internos $y$ en las formas de vinculación externa, aquellas mayores. ventajas y ayuda sólo podrán redundar en preservar y aun impulsar el modelo de "pais-sucursal".

\section{La Política Agrarla}

Por lo que se refiere a los cambios en la estructura productiva interna, uno de los más importantes y de mayor significación es el que atañe a la actividad agropecuaria. Dado el dinamismo de la demanda urbana de productos rurales - la población urbana crece con frecuencia al $5 \delta 6$ por ciento, el ingreso per capita urbano crece más que el promedio del país, una elevada proporción del sector industrial insume materiales de origen agropecuario y este sector crece con mayor rapidez que cualquier otra actividad- y dado que para los sectores urbanos de bajas rentas, que constituye una sustancial proporción de la población urbana, la alimentación representa una gran proporción de su gasto familiar, la tarea esencial de la política agraria tiene que ser la aceleración del ritmo de crecimiento de la producción rural total, y particularmente del excedente de producción agraria disponible para su exportación a las ciudades, todo ello a precios relativos, constantes, o mejor aún, decrecientes, al nivel del consumidor. Como esto tiene que ser compatible por otro lado con un aumento de los ingresos de los grupos rurales de bajas rentas - los grupos rurales y urbanos pobres son la base política de toda esta estrategia de desarrollo- será preciso poner el acento en: a) un incremento sustancial de los rendimientos físicos por hectárea y por hombre; b) la máxima eficiencia y reducción de costos en el proceso de comercialización; c) una disminución en el costo de los insumos agricolas, y d) una redistribución de ingresos dentro del propio sector rural. Estos son algunos aspectos básicos de la formidable y compleja tarea que corresponde realizar en la actividad agropecuaria para que este sector haga una contribución sustantiva -cconómica y politica- al proceso de desarrollo nacional, y mediante la ampliación del excedente exportable y la sustitución de importaciones, a la atenuación de la dependencia externa.

Dada la actual situación en matcria de tenencia de la tierra en América Latina, y las correspondientes circunstancias económicas, tecnológicas, sociales y politicas prevalecientes en el agro, la reforma agraria serí generalmente parte indispensable de una tal política agraria; pero a su vez, la propia 


\section{E. S T U D IOS INTER N A GIONALES}

reforma agraria deberi orientarse a cumplir los objetivos generales antes señalados de la polf́tica agraria y de da propia politica de desarrollo nacional.

\section{"Exportar o Morir"}

Uno de esos objetiros generales de mis trascendental importancia es.el aumento y diversificación de las exportaciones. No sólo por las razones tantas veces repetidas de la dependencia de un solo producto y de la inestabilidad correspondiente, sino porque el proceso de sustitución de importaciones ha llesaclo a lo que Prebisch ha llamado "la eliminación del margen comprimible de importaciones" $1 \tau$. Es decir, a una disponibilidad tan limitada de divisas, una vez descontado el servicio de los compromisos financieros externos, que súlo es posible importar bienes de producción y de consumo esenciales. De este nodo, ante cualquier situación desfavorable en los mercados externos o en la producción para exportación, las únicas alternativas son la contracción del consumo esencial y la actividad económica, o el endeudamiento externo adicional.

Por otra parte, en la medida en que la importación de bienes de capital representa una proporción elevada y creciente de las importaciones, las actividades de exportación han pasado a ser, de hecho, nuestras industrias de bienes de capital. El crecimiento de las exportaciones - sean agrícolas, pesqueras, mineras o manufactureras- viene a ser en consecuencia una expansión de nuestra capacidad real de ahorro y de inversión nacionales, requisito ineludible del desarrollo. La expansión acelerada de las exportaciones abre así la posibilidad de apoyar el crecimiento progresivamente en el ahorro nacional, o lo que es lo mismo, en la empresa de propiedad nacional. El estancamiento en las exportaciones exige en cambio, si se ha de mantener el ritmo. de crecimiento, mayor ahorro e inversión externos, coń el endeudamiento adicional consiguiente. Pero ello implica la desnacionalización creciente del patrimonio nacional: en términos de la propiedad física concreta de las empresas cuando el ahorro externo se aporta mediante capital privado extranjero, en términos de un derecho nominal sobre parte del patrimonio global de la nación, cuando el ahorro externo toma la forma de préstamo.

Como puede verse, en países que no poseen una industria nacional de bienes de capital suficientemente desarrollada, y que se encuentran en condiciones de una estructura de importaciones sin "margen comprimible", la propia posibiliclad del desarrollo nacional depende de la expansión de las exportaciones. De hecho, en esto ha raclicado la falla cintral de la politica de sustitución de importaciones: se ha sustituido la importacion de bicnes de consumo por la importación cie los bienes de capital y productos inter-

\footnotetext{
3:Raúl Prebich, "Desarrollo econórsico o estabilidad monetaria: el falso dilenta", capar., Boletix cronómico de Amsrice Latina, marzo de 1961.
} 
medios necesarios para producir aqueitos misnos bienes de cons:ano. Se has

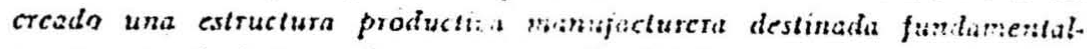
mente a producir para el conslino y se ha dejalo que el sictor exportador tradicional produza para la iniersión. Esia es la razón de fondo de que nise's. tro proceso de desarrollo se hrya hecho mis dependiente, mis vu?'nerable $y$ mis incslable.

Esta es también la razón fubdamental por la que se requiere una reorien. tación radical en materia de estratcgia del desarrollo. De una estrategia apoyada unilateralmente en la sustitución de importaciones debe pasarse en forma decidida a otra que se apoyc en tres pilares principales: a) la cxpansión y diversificación de las exportaciones; b) cambios estructurales internos en el sector agrícola, según se indicó, y en la actividad manufacturera, según se verá luego, y c) cambios básicos en la forma de las vinculaciones financieras externas.

Ahora bien, la expansión y diversificación de las exportaciones tropieza tanto en el caso de los productos tradicionales como en el de los manufacturados con dificultades bien conocidas y difícilmente superables con líricos Ilamados a la solidaridad internacional. Hay sin embargo, un elemento muy importante que influye decisivamente en aquellas dificultades para aumentar y diversificar las exportaciones y al cual rara vez se hace referencia. Me refiero al hecho de que las actividades exportadoras tradicionales de nuestros países son casi todas de propiedad privada extranjera, no siempre en la etapa productiva pero sí en la de la comercialización. Se trata concretarnente de empresas subsidiarias productoras de materias primas para la industria elaboradora matriz, localizada en un país industrializado, o sea, oligopolios internacionales integrados verticalmente. En consecuencia, el "comercio internacional" en estos casos pasa a ser un simple traslado de productos en proceso de la sección "extracción" o "cultivos" a la sección "elaboración". No exitre en estos casos ni mercado ni precio, y es imposible determinar el monto de las utilidades realizadas en la actividad primaria. Estas dependerán de una decisión arbitraria de la empresa con respecto al precio y serán función principalmente de la política impositiva de los países en que están localizadas la empresa matriz y la subsidiaria 19 .

Como con frecuencia la imposición a este tipo de empresas en los paises subdesarrollados ha llegado a ser más elevada que en los países industriales, el precio será fijado sumando al costo un porcentaje razonable de ganancia, resultando todo el remanente ser utiliclad de la fase de elaboración en el pais industrial. Por otra parte, dadạs las mayores economias. externas y de escala existentes para la elaboración en los paises inclustrializados, las empre-

25Francois Perroux: L'economie du F.Jime siccle, Paris, 1964.

Maurice Byc: Rdations ceonomiques isternationales, Paris, 1965.

Stephen Haymer: "Direct Forcign Investment and the Nationai Economic Interest", en Peter Russel, ed., Netionalism in Caneds, Toronto, 1966. 
sas tienden siempre a reservar esta fase del procesomparn ser realizada en el pais industrializado, $y$ esto ha llevado a una estructura tarifaria en que estos paises, para protegerse entre cllos, establecen una tarifa tipicancente elevada para el producto elaborado y baja para la materia prima. Esto sirve luego de justificación para evitar el desarrollo de las fases de elaboración en los paises productores primarios.

In la medida en que esta sea una explicación adecuada del funcionamiento de estas empresas, es evidente que existe un conflicto de interés entre el desco del pais exportador de maximizar sus ingresos de exportación y el del oligopolio internacional de maximnizar sus utilidades globales. Este conflicto no puede ser superado sino por la intervención directa en la empresa $y$ en su política de producción, elaboración, ventas, mercados y precios, ya sea mediante la nacionalización, la asociación con la empresa privada o el estado nacional, la supervisión estatal o alguna otra forma de intervención eficaz.

Habria aquí también amplio campo para elaborar fórmulas de cooperación internacional entre los paises exportadores de materias primas a fin de tener mayor capacidad de negociación frente a las grandes empresas, formular politicas impositivas coordinadas, intervenir en los mercados, regular la oferta, negociar cambios en la estructura tarifaria e impositiva de los países desarrollados, etc. El fruto de estas formas de cooperación puede ser altamente significativo si logra mejorar la relación de intercambio, ya que ello significa un traslado permanente de recursos adicionales al mundo subdesarrollado.

En otras palabras, el análisis anterior atribuye la incapacidad de lograr un mejoramiento en la.relación de intercambio, una mayor estabilidad en los mercados mundiales de productos básicos y un mayor grado de elaboración en las materias primas de exportación en forma determinante al carácter de las relaciones que se establecen entre empresas matrices elaboradoras en los países desarrollados y sus subsidiarias extractivas en los paises subdesarrollados. En consecuencia, la alteración de dichas relaciones en beneficio del país exportador sería el objetivo de la politica de desarrollo nacional, y para ello hay varios medios que están en manos de los gobiernos nacionales, y' respecto de los cuales hay incluso abundante cxperiencia. Trátase en todos lơs casos, evidentemente, de una intervención nacional en prácticas internacionales tradicionales que vienen siendo aceptadas desde mediados del siglo pasado $y$ que producirain por cllo fuerte resistencia en los intereses afectados. Es el. aspecto internacional de un programa nacional de transformaciones estructurales básicas y su lógico corolario. En el caso de América Latina, todos los países que pasaron por una revolución nacional -México, Bolivia, Cuba- nacionalizaron su sector exportador básico. En experiencias más moderadas de politicas naciomales de desarrollo, entre cllas la argentina, la venezolana y la chilena, el grado de contral esta- 
tal macional sobre la actividad exportadora básica aumentó sustancialmen: te $\mathrm{y}$ por medios diversos: monopolios de la comercialización (marketing board), control fiscalizador sobre las operaciones de las empresas exporta. doras, intervención en las politicas de precios y ventas, formación de empresas mixtas, desarrollo de la industria exportadora nacional pública, privada y mixta, acuerdos er tre países productores, etc.

Ya ha sido reconocido ampliamente que el desarrollo exige profundos cambios estructurales internos. Ya es hora de reconocer que ello es inseparable de profupdas transformaciones en los patrones habituales que caracterizan las vinculaciones económicas externas de nuestros países. $\mathrm{X}$ ya es hora, también, de apreciar que las medidas pertinentes no dependen enteramente de la buena voluntad de los países industriales, que han sido durante un siglo los principales beneficiarios de las ventajas de tales formas de vinculación, sino que dependen crecientemente de la voluntad de los propios gobiernos y países afectados. En el esclarecimiento de este problema, en la creación dẹ.fórmulas de transición creciente hacia el control nacional de los sectores bá:... os de exportación, en el examen de las posibles medidas de represalias y sus efectos, en el acopio de información. básica, en el análisis de experiencias pertinentes, en la asesoría técnica para las negociaciones, en el consejo administrativo y organizacional para la creación y funcionamiento de las nuevas instituciones y en muchos otros aspectos similares, hay un área vastísima y de trascendental importancia al que podrían dedicar un esfuerzo intelectual creador e imaginativo las ciencias sociales en América Latina y en otras regiones. En todos estos aspectos podrían aportar además un señalado servicio los organismos internacionales especializados, que pueden ser instruidos en tal sentido por los gobiernos de los paises interesados?

También en el campo de la tecnología hay que cumplir a este respecto una labor nacional $e$ internacional de gran trascendencia, que tendría que ser parte fundamental de la nueva política. La tradicional actividad exportadora ha carecido de estímulos para desarrollar una política dinámica e intensiva de cxplotación tecnológica innovadora en materia de recursos naturales en nuestros países -excepto al tratarse de actividades o recursos naturales que no existen en los paises industriales, como el caso de ciertos cultivos tropicales. En los demás casos, las grandes empresas internacionales que explotan materias primas tienen un conocimiento tecnológico acumulado a través de su experiencia con determinados recursos naturales, que los hace escudriñar el munclo con preferencia hacia aquella forma particular de presentación o tipo de recurso natural. Por ejemplo, si cierto mineral no se presenta con las caracteristicas que buscan las empresas que lo han explotado clurante largo tiempo, aq̣uel mineral, que desde el punto de vista nacional podria ser una

wvéase, por ejesnplo, Ix proposición de Dudley Seers: "Big Curupanies and Sunall Coun-

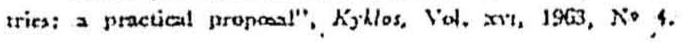


fuente importante de recursos si se desarrollara la tccnologia respectiva, no tiene ningún interés para el copital extranjero. En otros términos, en la medida en que el progreso técnico es el factor determinante fundamental de las ventajas comparativas, es absolutamente esencial impulsar dicho progreso tecnológico con el fin de valorizar los recursos naturales propios, asi como su máxima claboración.

\section{LA INYERSIGN PRIVADA EXTKANJERA}

El problema de la diversificación de las cxportaciones a nuestros países mediante la exportación de manufacturas tiene también limitaciones muy serias derivadas de la vinculación de gran parte de la industria nacional con empresas extranjeras. Sea que se trate de firmas subsidiatias o de empresas que fabrican productos bajo licencias y marcas extranjeras, la politica de las empresas matrices limita las actividades de las firmas que dependen de ella al mercado nacional, desalentando no sólo la exportación a los mercados de los países industriales, sino incluso a los demás países del área sub. desarrollada. En estos existirá otra empresa subsidiaria o que ha adquirido la licencia o marca respectiva, o bien el producto se obtendrá importándolo del país en que está radicada la casa matriz. Hay ejemplos bien conocidos de estas prácticas en la América Latina.

En consecuencia, aun cuando se obtengan facilidades tarifarias y de otro orden para las exportaciones de manufacturas a los paises industriales -e incluso a otros países subdesarrollados- el carácter dependiente de gran parte de la actividad manufacturera limitará seriamente las posibilidades de aprovechamiento de las oportunidades que se presenten.

La clásica inversión privada extranjera, o Ia imitación nacional de productos extranjeros mediante el uso de licencias y marcas patentadas, tiene otro inconvenientes severos además del recién citado. Por unà parte, inhibe podtrosamente el desarrollo tecnológico propio en la actividad manufacturera nacionaI. Considérese por ejemplo que fue necesaria una guerra mundial para que la industria automovilistica norteamericana produjera un vehículo -el jeep- apropiado a las necesidades de la vida rural en los países subdesarrollados. Por la otra, estimula la incorporación a la estruçura productiva nacional de aquellos patrones de producción de bienes de consumo conspicuo que impone el "efecto demostración" y que la política de limitación de las importaciones de bienes de consumo superluo se suponia que iba a evitar.

Otro problema que ya sc insinúa en muchos paises y que puede llegar a téner extrema gravedad es el monto que los comprom remesas de utilidades, dividencios, intereses, "royalties", pagos de servicios de administración y asistencia técnica, etc., pueden llegar a representar en la balanza de pagos. Un simple cjemplo aritmético ilustra el problema. Suponiendo que ia actividad manufacturera llegue a representar una tercera parte del ingreso nacional, que alrededor de la mitad del capital industrial llegue a 
ser de propicdad extranjera os esé produciendo productos bajo licencia extranjera, que se paguen tasas normaics de royalties y de utilidad y remesas al exterior $y$ que las tendenci.ts del comercio exterior mantengan su exparsión modernda, se concluye que cl conjunto de las remesas al exterior de las empres.as industriales podria llegar a representar de un 20 o 30 por ciento de la disponibiliclad total de divisas del pais, a lo que babria que agregar las remesas del sector exportador $y$ te otras actividades, y el servicio de la deuda externa. Podria parecer que una alternativa es obligar a las empresas extranjeras a que reinviertan sus utilidades en el pais. Pero eso llevaria a un proceso de desnacionalización de la; industrias nacionales existentes y a a una ampliación muy rápida y muy considerable de nuevas industrias extranjeras con respecto a las industrias nacionales; de todos modos se produciria una salida considerable de recursos una vez que la empresa extranjera hayz alcanzado el limite a su expansión dentro del mercado interno. Es un problema que por lo demás se ha estado planteando con gran calor, en debate público muy agudo y también en el medio académico, en países donde precisamente la inversión privada extranjera ha estado colocando en la última década sus capitales en forma masiva; es el caso de Canadí, de Australia y de varios paises europeos.

También en este aspecto de las vinculaciones económicas externas pareciera por consiguiente haber llegado el momento de buscar mecanismos que reemplacen o modifiquen la forma tradicional de absorber la tecnología moderna y el ahorro externo.

Una experiencia intert zuntísima a este respecto son los acuerdos de inversibn, comercio y préstamo que vienen celebrando los países socialistas con paises capitalistas europeos: el acuerdo entre la sociedad fLAT y la urss; entre una empresa francesa y la urss para la instalación de una fábrica de pasta para papel; entre la firma Krupp y Hungría para la construcción y exportación de una torre de distribución electrónica; entre la empresa inglesa Gallaghan y la sociedad de exportación checoslovaca Kovo; y entre la sociedad alemana occidental $\mathrm{BA}_{\mathrm{A}} \mathrm{D}$ y una organización polaca, ambos en el campo de la industria mecánica, etc.20. Estos acuerdos, denominados de "coproducción", se amplian y extienden rápidamente. Se han desarrollado entre Francia con Argelia (el acuerdo petrolero) y con Egipto (cultivo y comercialización de frutas y hortalizas), y tanto Japón como los propios Estados Unidos buscan realizar actualmente acucrdos similares con Yugoslavia, Rumania y la urss. Trátase en último término de sustituir el mecanismo tradicional de orientación y decisión del comercio y la inversión internacionales, radicado principalmente en los grandes oligopolios multinacionales verticalmente integrados, por acuerdos directos entre un centro de decisión auténticamente na-

2Estas informaciones y los comentarios que siguen estin basados en el interesantísimo trabajo del psofeso: Mraurice Być: "Cooperación en la producción y convergencia de los sistemas ecunómicos", Boletis de le Integración, julio IEC6, ixt.x., Buenos Aires. 
caonal $\mathrm{y}$ aquellas cmpreses multinacionales u otros centros de decisión radicados en otras maciones.

"La coproducción vincula dos centros de decisión que, luego de una negociación tendiente a salraguardar sus intereses mutuos, se ponen de acuerdo, a fin de alcanzar en común, en condiciones definidas y mediante aportes clefinidas, uno o varios objetivos determinados"... "lo que más nos interesa aqui son los tipos de coproducción que crean corrientes internacionales durables de intercambios que posibilitan un crecimiento internacionalmente equilibrado".

Según el profesor Byé, la coproducción presenta las siguientes caracteristicas:

"Io Vinculación institucionalizada entre centros de decisión.

“2 Participación, como centro de decisión del lado del país que recibe, de una institución que representa el interés general (Estado u organismo descentralizado de capitales públicos).

“g̣o Participación, como centro de decisión del lado del pajs de origen, ya sea de una firma privada o de un organismo de capital público (Estado u organismo descentralizado).

“40 Instalación de la institución de coproducción consecutivamente a acuerdos internacionales, los cuales o bien se conforman con admitir la posibilidad de alentar la ceación y de conjeturar sus condiciones generales (acuerdos comerciales de "cooperación" firmados entre países de Europa Oriental); o bien se expeñan en una creación especifica (acuerdos entre Estados, otorgados por la asociación franco-argelina de hidrocarburos, por una fábrica de amoniaco).

"5ọ Definición, a través del decreto que cree la Asociación, de un cierto número de condiciones, que en general pueden ser: modo de establecimiento de los planes y programas; financiación, incluyendo eventualmente adelantos de una de las partes; aporte técnico y p osecución de la investigación en común; posición a adoptar con respecto a los mercados; distribución de los resultados financieros; modalidad de reinversión.

"Go Definición del valor atribuido a los diversos "aportes" como elementos sometidos al control; apreciación de los aportes en "recursos naturales" que no son arrendados, sino asociados; apreciación del aporte y de los porcentajes de aporte en bienes de distintos órdenes (terrenos, edificios, infracstructuras, transportes...) ; apreciación del aporte de mano de obra. Los aportes nacionales son entendidos en el sentido de una contabilidad de existencias y de flujo nacional, $y$ no de una simple contabilidad financica (presupuesto de firma o presupuesto de Estado).

"o Revisión ce ajuda esperada por parte de los Estados o de las instituciones internacionales. Si, en paricular, et Estado de origen de los capitales en:- 
Ostaldo Sunkel / Politica nacional de desarrollo y dependencia externa

tiende que debe alentar la operación, adaptará su sistema de credito exterior a las necesidades de la nueva creación. Una revisión general de las formas de créditos con el fin de adaptarlas a la ayuda, sería la condición del cstablecimiento de un estatuto mundial de coproducción.

"Hemos de precisar que no está en nucstro pensamiento presentar la solución de coproducción como un modo exclusivo de regular los movimientos de capitales y de la ayuda. La consideramos tan só.o como un medio estratégico esencial para instaurar nuevas y más eficaces conexiones en el mundo. Pero, por un lado la inversión privada, y por el otro, las diferentes formas de ayuda, ambas conservan su función propia e importante":

La experiencia señalada antes y este concepto de la coproducción abren las puertas a formas nuevas de vinculación con la empresa privada extranjera en que es posible conservar los elementos altamente positivos que la empresá privada extranjera aporta -recursos financieros y capacidad y experiencia tecnológica, aủministrativa y de organización- y a la vez superar sus inconvenientes. Tratariase en concreto de lograr que la nueva actividad productiva creada en asociación con el capital público o privado extranjero se traspase progresivamente y en un plazo estipulado, tanto en propiedad y gestión, como cn capacidad tecnológica, al país, y que el pago del capital extranjero invertido se haga mediante la exportación de parte de la producción de la misma actividad y de otros productos que no se exportan habitualmente. Esta última es una de las características de los convenios de coproducción, y también de los préstamos para instalación de nuevas actividades productivas que realizan la uRss y otros países socialistas a paises subdesarrollados. Por lo demás, esta es la característica fundamental que hizo viable el modelo clásico de inversiones extranjeras en las áreas periféricas. Las transferencias masivas de recursos de capital del centro a la periferia fueron posibles justamente porque la inversión privada extranjera creaba un excedente exportable en la periferia, con cl que se financiaba aquella inversión externa. Con la industrialización sustitutiva de importaciones, al dirigirse crecientemente el capital externo al desarrollo de actividades internas que no contribuyen directamente a la cxpansión del excedente cxportabie. se ha ido creando un creciente desequilibrio entre las entradas de capital extranjero y la capacidad de scrvirlo adecuadamente. La nueva fórmula propuesta superaria este problema.

\section{La Polftica Industrial}

Finalmente, en el campo de la política industrial, también es preciso introducir nucvos conceptos y modificar hábitos y politicas que sc copian automáticamente de otras realidades.y que carecen de sentido $y$ funcionalidad en nucstras condiciones. 
Al amparo del sacrosanto principio de la competencia, por ejemplo, se ha permitido la proliferación indiscriminada de plantas que producen el mismo articulo, lo que ha llevado a una gran atomización de un mercado que de por si es pequeño y altamente estratificado. En consecuencia, la producción industrial se caracteriza por costos elevadísimos y una capacidad ociosa sustancial. Debido a su dependencia tecnológica exterma, se caracteriza por otra parte por producir artículos de tamaños, diseños, capacidades y características de manejo, mantención y otras correspondientes al consumidor medio norteame. ricano o europeo. Trátase en cambio de producir bienes manufacturaclos al alcance y adecuados para un gran mercado potencial de personas de bajos ingresos, en gran parte población rural. En lugar de una politica de puerta abierta incliscriminada y estímulo desmediclo a la industrialización sustitutiva y a la absorción tecnológica externa, debiera pasarse a una política restrictiva de prohibición de nuevas actividacles clonde haya capacidad ociosa instalada y de fomento de la concentración industrial en grandes unidades productivas especializadas, en lugar de las pequeñas unidades que producen de todo, habituales en la actualidad.

Creo que sólo la concentración en empresas de tamaño económico, con escalas de producción adecuaclas, $y$ especializadas en determinadas lineas o tipos de producción o procesos puede llevar a una vitilización adecuada de la capacidad instalada, a un aumento sustancial de la productividad, a rebajas considerables de costos y a la creación de unidades productivas que puedan acumular una masa de recursos suficientemente grande para dedicar parte de ellos a la investigación e innovación tecnológica y a un proceso acumulativo le ampliación de la capacidad productiva. No hay país del mundo que baya tenido éxito en su proceso cle industrialización que no haya entrado en esta fase de gran concentración industrial y gran empresa. Es más, el gran potencial productivo de las formas capitalistas de producción no se vino a manifestax en aumentos sustanciales y progresivos del ingreso nácional hasta que no se entró en esta fase de gran empresa y producción masiva. Esta es a mi juicio una etapa en que debe entrar la industrialización en la América Latina si ha de hacer un aporte realmente significativo y dinámico al desarrollo de nuestros paises. Aqui se plantea de nuevo el problema de la limitación de los mercados nacionales. En este punto la estrategia de desarrollo industrial se vincula por una parte con la política agraria a que he hecho referencia anteriormente, tendiente a ampliar los mercados internos de los grupos de bajos ingresos rurales y urbanos, y por otra con el papel que la integración puede cumplir en materia de consolidación y especialización de unidades productivas nacionales o multinacionales eficientes.

Por supuesto que la promoción deliberada de la concentración industrial plantea una dificultad considerable. que es el problema del poder cconómico y político de esas grandes concentraciones industriales. He aqui otro desafio a nuestra capacidad de inventiva para iclear o diseñar nuevas formas 
de control social sobre la gran enpresa que no afecte su Mexibilidad adini. nistrativa, no recargue burocráticamente su personal $y$ no introdtaca un scsgo antiinnovador y excesivamente conser ador en sus politicas, como vcurre con frecuencia con la empresa pública tradicional. Es también un cesafio a la organización de fucrzas sociales compensadoras con poder de negociación eficaz, en el área de los medianos y pequeños empresarios industriales y agricolas, en el de los consumidores, de la masa urbana y rural, etc., a tin de que todos puedan tener voz e influencia en la condueción de la politica económica nacional.

En materia de política industrial también ha quedado indicado ya que se viene agotando una fase en la politica de sustitución de importaciones, y que corresponde avanzar a la etapa de la producción de los productos intermedios básicos y de la industria mecainica. La posibilidad de desarrollar estas industrias en condiciones eficientes dependerá de la expansión de los merados de la industria nacional productora de bienes de consumo-que a su vez dependerá de la concentración y especialización de esta última, según acabo de explicar - y de su capacidad de exportación a paises de América Latina o a países desarrollados. Esto último dependerá, en gran medida, de que se formen empresas multinacionales con otros países de América Latina, según se señaló antes, y de que se logren acuerdos de coproducción con países industrializados.

Muchos otros aspectos de importancia habria que desarrollar en relación con las estrategias de desarrollo en el área de la política agraria, de las vincu. laciones externas y de la politica industrial, a que me he referido brevemente en las páginas anteriores. Igualmente habría que desarrollar las implicaciones de dichas estrategias en otros sectores claves, como la política educacional, por ejemplo. Pero el propósito de este trabajo no es ese. Es solamente el de señalar, a título de ilustración, algunas de las reorientaciones básicas que requeriría una política nacional de desarrollo, de mostrar la viabilidad téc: nica de las políticas correspondientes, de sugerir que la adopción de dichas políticas está al alcance de nosotros mismos y que no depende única ni principalmente del exterior, y de mostrar que es posible traducir una politica nacional de desarrollo en estrategias concretas que permiten interesar efectivamente a amplios sectores medios y populares, tanto urbanos como. rurales, con cayo apoyo se asegure la viabilidad politica del desarrollo nacional.

\section{LAS CONDICIONES EXTERNAS}

Queda por consiguiente una t́ltima interrogante fundamental: thasta dónde permitirán las limitacioncs impuestas por la trama de relaciones internacionales dentro de las cuales se encuentran nuestros paises que estos adopien politicas y estrategias de desarrollo nacional como las sugeridas en párrafos anteriores? O en otras palabras, dadas las repercusiones que una política de 
desartollo nacional tendria necesariamente sobre la forma de nuestras rincu. laciones externas, ¿serán to suficientemente poderosos los intereses externos c internos afectados para impedir dicha politica?

Creo que en esta materia estamos en mejores condiciones que hace algunos años atrás. Desde el punfo de vista interno, ya he sugerido que podrian existir las condiciones para que ideas de esta naturaleza pasen a formar parte de un programa, de una estrategia y de una ideología del desarrollo; y para que una combinación o alianza politica elabore sobre esa base su programa de acción. Con respecto al mundo exterior, al mundo capitalista dentro del cual nos desenvolvemos, la adopción de estrategias y de formas institucionales como Tas que se han sugerido probablemente habrian sido completamente inaceptables hace ocho o diez años atrás. Pero actualmente es posible ventilar estos problemas a la luz del día y nueras soluciones parecen factibles. Es que ha habido cambios fundamentales en el escenario internacional; cambios a los que se han referido algunos de los conferencistas que han participado en el ciclo de charlas inaugurales del Instituto de Estudios Internacionales de la Universidad de Ćhiler. Esos cambios se refieren a las relaciones entre los dos principales bloquies imundiales y particularmente a las relaciones entre las dos superpotencias. Desde que la crisis de Cuba hizo evidente que Ia interferencia directa de una de'las grandes potencias en el área de influencia de la otra acarreaba el riesgo de la guerra nuclear, se ha llegado a una especie de entente entré ellas. En clecto, el equilibrio nuclear ha hecho de la guerra directa entre las dos grandes potencias una forma no viable de polftica exterior. Desaparecida la amenaza de la agresión mutua directa, las potencias hegemónicas han tenido que, y han podido, atenuar el rigido control y perfecta alineación que exigian detrás de cada una de ellas a las potencias intermedias y a los paises subdesartollados adscritọs a su área de influencia. Ello ha hecho posible el surgimiento de paises intermedios relativamente independientes de sus respectivas potencias hegemónicas, y la adopción de innovaciones importantes en la politica de desarrollo en esos paises para adecuarla en forma más apropiada a las condiciones nacionales. Es el caso de las transformaciones que han venido ocurriendo en las economías socialistas de Europa Oriental y de la reorientación de la política de cooperación internacional que representó la Alianza para el Progreso para América Latina. Esos paises intermedios, relativamente avanzados, no estaban seguramente muy cómodos dentro de normas más o menos rigidas de alineación completa y total con los dos grandes bloques en pugna. Incluso internamente en cada superpotencia se ha producido un proceso de liberalización, de disminución del rigor del control. Tanto así que en la Unión Soriética se ensayan nucvas formas de organizar la producción, que tienden hacia una relativa liberalización del sistema. Por el lado del control sobre las potencias satélites, los paises

ilet los articulos de Richard Colt y Caudio Vëliz en Estadios.Jaternacionales, Yol, 1, X. 1: y de Jacuues Vernart, Rirkerd Lówenthal y Alain Jase en el Vol. t, No 2 de la mistna revista. 
socialistas de Europa Oriental surgen con un grado de libertad de decisión mucho mayor que antes en cuestiones internas, $y$ hasta cierto punto incluso en ma. teria de politica internacional. l' lo mismo ha pasado dentro del bloque capitalista, en parte por el surgimiento de Europa Occidental como potencia cconómicamente poderosa, particularmente el caso de Francia. Incluso dentro de la América Latina, en donde el programa de la Alianza para el Progreso, por lo menos en su concepción inicial y en los resabios que de él quedan, también aprobaba este deseo de ensayar nuevas fórmulas, de ver formas alternativas de visualizar el desarrollo del mundo subdesarrollado. Esta adopción de actitudes positivas frente a las posibilidades de cambio en los paises subdesarrollados de ambos bloques está vinculada sin duda con el hecho de que la confrontación nuclear directa entre las grandes potencias es imposible. ¿Cuáles son entonces las formas en que esa confrontación se puede dar? Una forma es evidentemente la lucha ideológica, particularmente en el plano del desarrollo. Se trataria de mostrar al mundo de parte de cada uno de los bloques, que el desarrollo de los paises subdesarrollados sólo puede hacerse por la vía capitalista, o que tiene que hacerse por la via socialista. De modo que ha adquirido intérćs para las potencias dominantes, incluso teniendo conciencia de que se corren ciertos riesgos, ensayar fórmulas que permitan llevar a un desarrollo más acelerado y más satisfactorio, sin una ruptura básica del sistema político imperante.

Este proceso ha tenido como efecto no sólo el "deshielo" interno en cada sistema, sino también la proliferación acclerada de las relaciones entre los países de cada bloque. Los últimos cinco o seis años muestran una evolución clara $y$ evidente en este sentido, tanto en el plano del comercio internacional como en el de las relaciones políticas y también en lo que se refiere a las relaciones culturales internacionales. Los paises del mundo subdesarrollado, antes afiliados muy directa y exclusivamente a su potencia hegemónica, están teniendo en efecto posibilidades muy amplias de intercambio comercial, de ayuda externa, de contacto cultural, de consulta, de asesoría técnica, de discusión ideológica, de formas de vinculación cultural, de intercambio de estudiantes y profesores, de intercambio de investigaciones, con paises del bloque opuesto,

El "deshielo" interbloques se inició primero y adquirió mayor vigor, como era de esperar, especialmente entre los paises intermedios de cada bloque, para extenderse lentamente a las propias potencias hegemónicas y luego a los paises dependientes. Con respecto a estos últimos, que son los más numerosos y engloban una gran proporción de la población mundial, ellos se encuentran hoy en una situación muy especial. Por una parte, dado que la intervención militar directa de una de las potencias hegemónicas en un pais englobado en el área de dominación de la otra conduciría a la conflagración nuclear, puede suponerse que en caso de movimientos revolucionarios en un pais subdesarrollado, estos movimicntos no podrán contar con apoyo militar y ccond́nico cxterno abierto y declarado de la gran potencia respectiva, en tanto que contari con tal apojo masivo $y^{\prime}$ declarado de su respectiva 
potencia hegemónica el gobierno del pris cn cucstión. En otras palabras, las posibilidades de que los movimientos de guerrilla se expandan, que se conviertan en revolución y guerra civil y que finalmente triunfen, parece, al menos en la América Latina, una posibilidad por ahora remota. Excluida la posibilidad revolucionaria ¿significa ello la retrogradación al stalus quol Me parece que no. La posibilidad de polfticas progresistas en la América Latina dependerá evidentemente en primer lugar de la estructura de las fuerzas sociales internas, del grado de integración nacional, del grado de legitimidad del gobierno y de otras circunstancias internas. Pero en el caso en que tales circunstancias estén presentes en mayor o menor medicla, los límites de la política de desarrollo podrán, a mi juicio, ampliarse considerablemente más allí de lo tradicional.

Las consideraciones principales que apoyan esta tesis se enumeran a continuación:

Primero, el peligro de cambio revolucionario interno ha sido prácticamente climinado, tanto por la entente interpotencias como por la reorganización de los ejércitos nacionales para hacer frente a la "defensa interna". La posibiliclad de la guerra externa está excluicla, tanto entre las grandes potencias, por las razoncs ya señ̉aladas, como entre los satélites de una misma potencia, porque ésta no la toleraria y está en condiciones de impedirla dada la dependencia económica y militar de los satélites.

Segundo, porque se ha hecho evidente -las declaraciones y concepciones de la Alianza para el Progreso, aunque no se apliquen siempre seriamente constituyen hechos irreversibles- que los peligros y tensiones revolucionarias en Ia América Latina tienen su origen profundo en la estructura económica y social de estos países. En consecuencia, éstas deben modificarse, pero sólo en los casos en que haya capacidad politica interna para llevar a cabo esa transformación sin riesgos de desborde revolucionario, puesto que lo que también se ha comprendido es que el propio proceso de cambio tiene una dinámica de tensiones y presiones potencialmente revolucionarias, igual que la pretensión de mantener el status quo más allá de lo posible.

Tercero, porque se han venido ampliando los contactos de todo orden entre nuestros paises y todos los otros, en desmedro de las vinculaciones exclusivas con la potencia hegemónica; contactos incrementados con las potencias intermedias y satélites del propio bloque, asi como contactos con la potencia dominante alternativa, y con los paises intermedios y con los satélites del otro bloque. Esto significa concretamente fuentes alternativas de comercio, financiamiento, asistencia técnica, recursos humanós, consulta respecto de determinadas polfticas, formación e investigación y visión cultur 1 , as l como mayor aproximación en bloques ya sea geografficos (integración latinoamericana) o de interés (UxCTAD).

Cuarto, la propia potencia hegcmónica pondrá todo su peso decrís de lograr los dos objetivos siguientes, en importancia decreciente: a) evitar situa- 
ciones prerterolucionarias, y b) fomertar el desurro!lo. En primer lagar tratarí de cstabilizar, contencr y congelar situsciones potencialmente expiosivas, fómentando en estos casos deliberadanente cl control militar de la situacion. en casos extremos, pero tratando de todos medos que cstos grupos militates desempeñen un papel modernizante y progresista. Naturalmente que de tal programa sólo se cumplirá la primera parte, la toma del poder por los militares, pero no la segunda, ya que la presencia dic éstos cn el pocler significa necesariamente la aglutinación de las fuerzas reaccionarias en torno a ellos y la destrucción de los grup os intelectuales y sindicales y de los particlos de masa, en los cuales podría apoyarse una politica progresista. En los paises sin una sólida y efectiva constclación politica progresista interna, el apoyo externo conduce probablemente a la situación contraria, a un fortalecimiento de las condiciones para la preservación del slatus quo. En los paises que cuenten con una situación politica que esta bajo control y que ensayan seriamente politicas de desarrollo y de cambio estructural, se da el caso más favorable desde el punto de vista de la potencia hegemónica, y estos paises contarán probablemente con amplio apoyo y ayuda externa, aun cuando sus métodos se salgan de la ortodoxia.

En último término entonces, daclos los cambios que han venido ocurriendo en el escenario politico internacional, me parece que la posibilidad de llevar a cabo una politica de desarrollo nacional depende en lo fundamental de la situación interna, es decir, del grado de diferenciación de la estructura social, del grado de participación politica de la población y de la existencia. o formación de un movimiento político no tradicional que constituya una respuesta funcional a la problemática sociopolítica concreta en términos de un programa, de una estrategia y de una ideologia de desarrollo nacional.

Para terminar, resumo lo que he querido sugerir a través de estas reflexiones, que no tienen otro propósito que el de estimular un debate algo más positivo sobre estos asuntos que el que hemos tenido hasta ahora. Lo que he tratado de hacer es lo siguiente: aceptar que el desarrollo nacional es el objetivo fundamental de la politica de desarrollo; en segundo lugar, señalar que el cumplimiento del objecivo de reducir la dependencia externa requiere reorientaciones muy importantes en la estrategia de desarrollo tradicional, particularmente en lo que se refiere a la política agraria, a la integración, a las formas de vinculación externa $y$ a la política industrial; en tercer lugar, indicar que vienen ocurriendo en algunos paises de la América Latina cambios y transformaciones estructurales que parccerian indicar la posibilidad, la potencialidad, de que tales nuevas politicas se puedan formular y se puedan aplicar; en cuarto lugar, sugerir que en csos casos particulares, los cambios en la situación internacional parecerian haber creado condiciones suficientemente tolerantes y flexíbles como para pernitir la aplicación de politicas de desarrollo nacional. 